\title{
Prognosis and Long-Term Overall Survival in Hypertensive Patients Undergoing Chronic Hemodialysis: A Multicenter Parametric Mixture Split-Population Analysis
}

\author{
Vahid Ebrahimi, PhD; Mehrdad Sharifi, MD²,3 Mohammad Hossein Khademian, MSc ${ }^{4}$; Peyman Jafari, PhD; Shahrokh Ezzatzadegan \\ Jahromi, MD $^{5}$; Samaneh Sabouri, PhD $^{{ }^{*}}$ \\ ${ }^{1}$ Department of Biostatistics, School of Medicine, Shiraz University of Medical Sciences, Shiraz, Iran \\ Emergency Medicine Department, School of Medicine, Shiraz University of Medical Sciences, Shiraz, Iran \\ ${ }^{3}$ Emergency Medicine Research Center, Shiraz University of Medical Sciences, Shiraz, Iran \\ ${ }^{4}$ Department of Medical Surgical Nursing, School of Nursing and Midwifery, Shiraz University of Medical Sciences, Shiraz, Iran \\ ${ }^{5}$ Department of Medicine, School of Medicine, Nephrology Urology Research Center, Shiraz University of Medical Sciences, Shiraz, Iran
}

\begin{abstract}
Background: Hemodialysis (HD) patients face long-term complications which require ongoing dialysis and follow-up. The management of hypertension among HD populations has often been neglected. This study aimed at identifying the determinants of death in hypertensive HD (HTN-HD) patients.

Methods: In a multicenter retrospective cohort study (conducted from 2005 to 2018 in thirty-four HD centers affiliated with Shiraz University of Medical Sciences), the data of 725 HTN-HD patients who had at least 3 months of regular dialysis and follow-up were analyzed. Accelerated failure time mixture split-population (AFTMSP) regression was utilized to identify the factors with significant effects on long- and short-term overall survival (OS) separately.

Results: Among the different AFTMSP models, the extended generalized gamma (EGG) model outperformed the others. Sex (male: event time ratio $[E T R]=1.30$ ), initial vascular access type (arteriovenous fistula: $E T R=1.50$ ), and the type of membrane flux used for HD (high-flux: ETR =1.27) had important impacts on short-term OS. Moreover, age $(\mathrm{OR}=1.06)$, dialysis adequacy (Kt/ $\left.V_{\text {urea }} \leq 1.2: \mathrm{OR}=2.30\right)$, initial vascular access type (central venous catheter: $\left.\mathrm{OR}=2.08\right)$, serum sodium $(\mathrm{OR}=0.90)$ concentration, and potassium $(\mathrm{OR}=0.66)$ concentration had significant effects on long-term OS.

Conclusion: The split-population analyses were able to demonstrate that the predictors of long-term OS were different from those of short-term OS. Although the superiority of the parametric EGG model was proved in this study, further research with different databases is suggested. Moreover, these findings can be considered by health policy decision-makers to create a new guideline to enhance the long-term OS of HTN-HD patients.

Keywords: Central venous catheter, Hemodialysis, Hypertension, Survival

Cite this article as: Ebrahimi V, Sharifi M, Khademian MH, Jafari P, Ezzatzadegan Jahromi S, Sabouri S. Prognosis and longterm overall survival in hypertensive patients undergoing chronic hemodialysis: a multicenter parametric mixture split-population analysis. Arch Iran Med. 2021;24(11):828-836. doi: 10.34172/aim.2021.123
\end{abstract}

Received: November 12, 2020, Accepted: February 7, 2021, ePublished: November 1, 2021

\section{Introduction}

Hemodialysis (HD) is a known option for renal replacement therapy. It prolongs the life of patients with end-stage renal disease, improves their quality of life, and reduces death from uremia. ${ }^{1-3}$ Among various comorbid illnesses associated with this problem, hypertension is mentioned as the main one..$^{4-6}$ According to the reports, $18-41 \%$ of patients with hypertension may need renal replacement therapy in the acute phase and the prevalence of hypertension varies from $70 \%$ to $90 \%$ among $\mathrm{HD}$ patients. ${ }^{7,8}$ Hypertension is the initial cause of end-stage renal disease in about $30 \%$ of Iranian patients undergoing HD. ${ }^{5}$ The overall survival (OS) rate of $\mathrm{HD}$ patients is different in developed and developing countries. ${ }^{9,10}$ In the Iranian population, the mortality rate of $\mathrm{HD}$ patients is about $30-50 \%$ and their five-year OS rate is almost $18-23 \%$. $^{11,12}$
Several studies have been conducted to investigate the associated determinants of the short-term OS of patients under HD. ${ }^{5,12-21}$ Epidemiological studies have demonstrated that several covariates affect $\mathrm{HD}$ patients' OS rate including sex, body mass index (BMI), comorbid illnesses, and blood cell indices (including mean corpuscular hemoglobin concentration [MCHC], hemoglobin, red blood cell [RBC], white blood cell [WBC], albumin, cholesterol, high-density lipoprotein [HDL], and uric acid). In some cases, there is a direct association between a risk factor and mortality, while some risk factors have an opposite effect on the outcome of interest. ${ }^{5,12,14,16-18,20}$

HD patients may experience death before kidney transplantation. ${ }^{2,9,12}$ Therefore, it is necessary to determine the predictors that contribute to the patients' OS. As an appropriate statistical procedure, the methodology of 
survival analysis is utilized to model the association between the covariates and mortality in survival time data. ${ }^{22-24}$ Among the various approaches to model timeto-event data, the multiple covariate Cox proportional hazards $(\mathrm{PH})$ model is the most popular method because it has fewer model assumptions. ${ }^{23-25}$ Using the Cox model, the hazard function at time $t$ for a subject with a given set of explanatory covariates can be obtained by the product of an exponential function of the linear combination of the covariates and an arbitrary baseline hazard function..$^{23,24}$ The Cox PH model is semiparametric because the baseline hazard function is completely unspecified. ${ }^{24}$ The $\mathrm{PH}$ assumption of the Cox model needs to be checked for each covariate before the interpretation of the results. ${ }^{22,24}$ The review of past studies indicated that this assumption had not been checked in most of them. ${ }^{26}$ As an alternative to the Cox PH approach, parametric survival analyses have been proposed in which the mathematical form of the survival time (i.e. the outcome) is completely determined. ${ }^{27}$ Moreover, simulation studies have demonstrated that parametric survival models are more powerful than semiparametric ones, provided that the functional form of the survival time is appropriately specified. Many parametric survival models are accelerated failure time (AFT) models in which survival time is modeled as a function of covariates. ${ }^{24,27}$

Though dialysis could improve mortality and morbidity rates, long-term OS remains poor. In some cases, the long plateau at the end of the non-parametric KaplanMeier (NPKM) survival probability plots can lead to the violation of the $\mathrm{PH}$ assumption. ${ }^{28,29}$ This occurs when the follow-up time is long and a high percentage of subjects have not experienced the event of interest at the end of the study. In such cases, using split-population (SP) models may be the best option. ${ }^{28,29}$ The two major platforms of the SP models are non-mixture and mixture. Mixture split-population (MSP) models are the most common approaches that are widely utilized for modeling survival data with long-term OS fraction. ${ }^{28,30}$ In contrast to the standard Cox $\mathrm{PH}$ regression, which is an appropriate method for determining the predictor variables associated with short-term OS, MSP models can identify the effect of risk factors on both short- and long-term OS separately. ${ }^{29,30}$

Considering the limited data in the literature, the current study attempts to identify the prognostic determinants contributing to either the long- or the short-term OS of hypertensive hemodialysis (HTN-HD) patients using the parametric MSP model.

\section{Materials and Methods Sampling Population}

The data of this multicenter cohort study were retrospectively extracted from the electronic database and the paper documents of Special Diseases Administration, affiliated to Shiraz University of Medical Sciences (SUMS), in southern Iran. These data included the information of thirty-four HD centers and since there was no electronic information for the patients before 2012, paper medical records were used as well. Hypertensive subjects above 18 years of age who survived the initial three months on maintenance HD were included. Moreover, patients were excluded in the case of incomplete data on important determinant factors, death in the first three months, switching from HD to peritoneal dialysis, kidney transplantation, unknown current status, and loss of regular follow-up for any reason. Therefore, of 2253 patients undergoing chronic HD, a total of 725 hypertensive patients were eligible for analysis during the period from 2005 to 2018. In addition, the HD patients in the database who survived until their last follow-up were censored.

\section{Clinical and Demographical Features}

The demographic characteristics of the subjects including sex, age, and BMI were gathered. The laboratory features and the indices related to the HD sessions were repeatedly and regularly collected from the fourth month of starting HD onwards. The laboratory factors including serum creatinine, blood urea nitrogen (BUN), fasting blood sugar (FBS), total WBC count, hematocrit, serum hemoglobin concentration, mean cell volume (MCV), mean cell hemoglobin concentration $(\mathrm{MCH}), \mathrm{MCHC}$, albumin, low-density lipoprotein (LDL), HDL, uric acid, triglyceride, cholesterol, iron, total iron-binding capacity (TIBC), parathyroid hormone (PTH), ferritin, alkaline phosphatase (ALKPH), and the serum concentrations of potassium, phosphate, calcium, and sodium were extracted from the database. The patient samples were not centralized in a single laboratory and were evaluated in the laboratories of the HD centers.

Additionally, the factors associated with the HD sessions such as ultrafiltration volume, systolic and diastolic blood pressures, average time of dialysis per session, pre- and post-dialysis weights, adequacy of $\mathrm{HD}$, blood flow rate, type of membrane flux (low-flux or high-flux), and initial vascular access type (arteriovenous fistula [AVF] or central venous catheter $[\mathrm{CVC}]$ ) were also recorded. The high-flux $\mathrm{HD}$ membrane is defined as a $\beta_{2}$-microglobulin clearance of $>20 \mathrm{~mL} / \mathrm{min}$ and has larger pore size than the lowflux HD membrane. ${ }^{31}$ In addition, the adequacy of HD was measured by single-pool Kt/ $\mathrm{V}_{\text {urea }}{ }^{32}$ Since the Kidney Disease Outcomes Quality Initiative (KDOQI) group adopted the $\mathrm{Kt} / \mathrm{V}_{\text {urea }}$ of 1.2 as the standard for adequacy of dialysis, in the current study, $\mathrm{Kt} / \mathrm{V}_{\text {urea }}$ of 1.2 was considered as the optimal cut-off point for categorizing this factor. ${ }^{33}$

\section{Statistical Analyses}

In medical research, we deal with time-to-event data when the outcome variable of interest is the time until an event occurs. An important characteristic of these data is censorship which occurs when the data about the survival outcome variable are incomplete. ${ }^{24}$ In this study, the survival time was censored if the desired event (i.e. death) did not happen until the last follow-up time. Split-population (SP) models can handle data with a high 
percentage of censorship more efficiently than traditional survival models such as the Log-rank test and the Cox PH regression. ${ }^{28-30,34}$

During survival analysis, we sometimes face a fraction of subjects who never experience the event of interest and are called 'non-susceptible' subjects (or long-term survivors), whereas the others are regarded as susceptible subjects (or short-term survivors). In such circumstances, the plot of the standard NPKM estimates has a long plateau even with a long follow-up time. ${ }^{28,29,34}$

The general formula for the MSP models is given in the Appendix. These models can be used parametrically or semi-parametrically. ${ }^{29,30,34}$ In parametric MSP models, the distribution of the outcome variable is determined in terms of the unknown parameters. Therefore, the mathematical forms of the hazard and survival functions can be specified. ${ }^{24,29}$ Before using the SP models, two main assumptions should be checked: 'testing the presence of long-term survivors' and 'testing the sufficient follow-up time. To check these two assumptions, the NP statistical tests suggested by Maller and Zhou can be utilized, especially when there is shortage of clinical experience and biological evidence. ${ }^{28}$

The variables were chosen based on both clinical and statistical significance found in univariate MSP analyses (if the $P$-value of the covariate was $<0.2$ in the univariate MSP model, the covariate became a candidate for entering the multiple MSP model).

In order to distinguish the best functional form of the survival time, eight parametric accelerated failure time MSP (AFTMSP) models were fitted including exponential, Rayleigh, Weibull, log-logistic, generalized log-logistic, gamma, extended generalized gamma (EGG), and generalized F (GF) distributions..$^{34,35}$ In the next step, the model with the lowest Akaike's information criterion (AIC) was chosen as the best parametric model. ${ }^{24,35}$ In the parametric AFTMSP framework, the probability of having long-term survival can be modeled using a logistic regression model (see online Supplementary file 1). Moreover, an AFT model from the generalized F distribution family can also be utilized for modeling the short-term survivors. The effects of the covariates on time were modeled by the scale parameter of the distribution. ${ }^{35}$ Using the AFTMSP, it would be possible to calculate the odds ratio (OR) estimates for the long-term survivors and the event time ratio (ETR) estimates for the short-term survivors in terms of the covariates associated with the desired event. ${ }^{24,29,35}$ The statistical analyses were done in $\mathrm{R}$ software (version: 3.6.2) using the ' $g$ fcure' package. ${ }^{35}$

\section{Results}

In this multicenter retrospective cohort study, 959 hypertensive patients undergoing HD were followed and investigated. According to the exclusion criteria, patients who had incomplete information $(n=160)$, those who underwent kidney transplantation $(n=45)$, recovered from HD $(n=16)$, switched to peritoneal dialysis $(n=1)$, or were transferred to other HD centers $(n=12)$ were omitted. Finally, 725 eligible HTN-HD patients (females: $\mathrm{n}=296,40.8 \%$ ) entered the study and were analyzed. The details of the demographic data including laboratory values and dialysis factors are reported in Table 1. The findings of the paired Student's $t$ test indicated a significant decrease in mean BUN (mean \pm SD before HD: $56.0 \pm 15.7 \mathrm{mg} / \mathrm{dL}$; mean \pm SD after HD: $18.9 \pm 8.0 \mathrm{mg} / \mathrm{dL})$ and serum creatinine (mean \pm SD before HD: $6.8 \pm 2.5 \mathrm{mg} /$ $\mathrm{dL}$; mean \pm SD after HD: $2.9 \pm 1.1 \mathrm{mg} / \mathrm{dL})(P<0.001)$.

The restricted mean survival time was 3094 days (95\% CI: 2804-3384 days). Using the NPKM approach, the overall one-, two-, three-, four-, five-, and fourteenyear survival rates $(95 \% \mathrm{CI})$ were $86.5 \%(83.7-89.0 \%)$, $73.9 \%$ (69.9-77.5\%), 67.9\% (63.3-72.1\%), 63.7\% (58.3$68.6 \%), 57.8 \%(50.8-64.2 \%)$, and $55.5 \%(47.3-63.0 \%)$, respectively (Figure 1). The results of the NP Log-rank test (Figure 2$)$ showed that being male $(P=0.047)$, having AVF as vascular access $(P<0.0001)$, and using high-flux HD membranes $(P=0.046)$ were associated with higher OS rates. In addition, patients with $\mathrm{Kt} / \mathrm{V}_{\text {urea }}$ of $>1.2 \mathrm{had}$ marginally higher levels of OS compared to the others $(P=0.098)$.

From Figure 1, it can also be observed that the estimated survival function leveled off at a non-zero probability (around 0.55) and that no further deaths happened after five years of follow-up. The percentage of censored observations $(\approx 76 \%$ or three-fourth of all observations) and the result of Maller and Zhou's test confirmed the existence of long-term survivors in the study population $\left(C_{0.01}=0.94>\hat{\mathrm{p}}_{\mathrm{n}}=0.45\right)$. Furthermore, the NP test statistics suggested by Maller and Zhou confirmed the assumption of the sufficient follow-up time as well $\left(\mathrm{C}_{0.95,2}=0.0014<\mathrm{q}_{\mathrm{n}}=0.24\right)$. As a result, using the parametric AFTMSP model to assess the effects of the covariates on the survival of both short- and long-term groups separately was approved.

\section{The Short- and Long-term OS of the HTN-HD Patients}

After fitting eight different parametric AFTMSP models, the EGG distribution had the best performance with the lowest $\mathrm{AIC}=949.2$ (Table 2). The results indicated that sex (male, ETR [95\% CI]: 1.30 [1.01-1.64], $P=0.045$ ) and initial vascular access type (AVF, ETR [95\% CI]: 1.50 [1.13-1.99], $P=0.005)$ had significant impacts on the short-term survival time. Moreover, the type of membrane flux used for HD was marginally associated with the short-term survivors (high flux, ETR [95\% CI]: 1.27 [0.99-1.65], $P=0.064$ ). This means that the median short-term OS time of males was 1.3 times higher than that of females. In addition, having AVF as vascular access and using high-flux HD membranes were associated with a higher short-term OS time compared to having CVC as vascular access and low-flux membrane dialyzers (Table 3).

Investigating the long-term OS of patients demonstrated that age (OR [95\% CI]: 1.06 [1.04-1.08], $P<0.001$ ), initial vascular access type (CVC, OR [95\% CI]: 2.08 [1.093.98], $P=0.027$ ), and serum sodium concentration (OR 
Table 1. Descriptive Characteristics and Laboratory Values of HD Hypertensive Patients $(\mathrm{N}=725)$

\begin{tabular}{|c|c|}
\hline \multicolumn{2}{|l|}{ Demographics Characteristics } \\
\hline \multicolumn{2}{|l|}{ Gender, No. (\%) } \\
\hline Male & $429(59.2)$ \\
\hline Female & $296(40.8)$ \\
\hline \multicolumn{2}{|l|}{ Last status, No. (\%) } \\
\hline Dead & $173(23.9)$ \\
\hline Censored $^{a}$ & $552(76.1)$ \\
\hline Age $(y)$ & $63.2(16.5)$ \\
\hline $\mathrm{BMI}\left(\mathrm{kg} / \mathrm{m}^{2}\right)$ & $22.7(4.2)$ \\
\hline \multicolumn{2}{|l|}{ Laboratory Values, Mean $( \pm S D)$} \\
\hline Albumin $(\mathrm{g} / \mathrm{dL})$ & $3.8(0.4)$ \\
\hline PTH (pg/mL) & $231.6(79.9)$ \\
\hline Phosphate (mg/dL) & $4.9(1.1)$ \\
\hline Calcium (mg/dL) & $8.6(0.8)$ \\
\hline Potassium (mEq/L) & $5.0(0.6)$ \\
\hline Uric acid (mg/dL) & $6.7(0.9)$ \\
\hline Sodium $(\mathrm{mEq} / \mathrm{L})$ & $138.4(3.6)$ \\
\hline ALKPH (IU/L) & $320.9(119.0)$ \\
\hline Triglyceride (mg/dL) & $297.0(15.5)$ \\
\hline HDL (mg/dL) & $36.5(3.5)$ \\
\hline $\mathrm{LDL}(\mathrm{mg} / \mathrm{dL})$ & $97.1(11.7)$ \\
\hline Cholesterol (mg/dL) & $179.0(14.5)$ \\
\hline Ferritin $(\mu \mathrm{g} / \mathrm{L})$ & $360.6(207.1)$ \\
\hline $\mathrm{TIBC}(\mu \mathrm{g} / \mathrm{dL})$ & $267.0(40.1)$ \\
\hline Iron $(\mu \mathrm{g} / \mathrm{dL})$ & $89.3(55.8)$ \\
\hline Hemoglobin (g/dL) & $10.6(1.9)$ \\
\hline WBC $\left(10^{6} / \mu \mathrm{L}\right)$ & $9.9(11.0)$ \\
\hline MCV (fL) & $85.9(7.2)$ \\
\hline HCT $(\%)$ & $33.8(5.2)$ \\
\hline MCH (pg/cell) & $26.9(2.7)$ \\
\hline $\mathrm{MCHC}(\mathrm{g} / \mathrm{dL})$ & $31.1(1.4)$ \\
\hline FBS (mg/dL) & $128.4(52.0)$ \\
\hline \multicolumn{2}{|l|}{ Dialysis Factors } \\
\hline UF $(\mathrm{mL})$, Mean $( \pm \mathrm{SD})$ & $1845.0(825.9)$ \\
\hline Systolic BP (mm Hg), Mean $( \pm$ SD) & $130.1(15.7)$ \\
\hline Diastolic BP (mm Hg), Mean $( \pm \mathrm{SD})$ & $77.6(7.7)$ \\
\hline Average time of dialysis per section $(\mathrm{min})$, Mean $( \pm \mathrm{SD})$ & $236.3(29.3)$ \\
\hline Pre-dialysis weight $(\mathrm{kg})$, Mean $( \pm \mathrm{SD})$ & $63.6(12.6)$ \\
\hline Post-dialysis weight $(\mathrm{kg})$, Mean $( \pm \mathrm{SD})$ & $61.8(12.6)$ \\
\hline $\mathrm{Kt} / \mathrm{V}_{\text {urea }}$ Mean $( \pm \mathrm{SD})$ & $1.3(0.3)$ \\
\hline Blood flow rate $(\mathrm{mL} / \mathrm{min})$, Mean $( \pm \mathrm{SD})$ & $373.3(27.0)$ \\
\hline \multicolumn{2}{|l|}{ Type of membrane flux, No. (\%) } \\
\hline Low-Flux & $253(34.9)$ \\
\hline High-Flux & $472(65.1)$ \\
\hline \multicolumn{2}{|l|}{ Initial vascular access type, No. $(\%)$} \\
\hline AVF & $401(55.3)$ \\
\hline CVC & $324(44.7)$ \\
\hline
\end{tabular}

BMI, body mass index; ALKPH, alkaline phosphatase; AVF, arteriovenous fistula; BP, blood pressure; CVC, central venous catheter; FBS, fasting blood sugar; $\mathrm{HCT}$, hematocrit; $\mathrm{HDL}$, high-density lipoprotein; $\mathrm{Kt} / \mathrm{V}_{\text {urea' }}$ adequacy of dialysis; LDL, low-density lipoprotein; $\mathrm{MCH}$, mean cell hemoglobin concentration; $\mathrm{MCHC}$, mean corpuscular hemoglobin concentration; MCV, mean cell volume; PTH, parathyroid hormone; SD, standard deviation; TIBC, total iron binding capacity; UF, Ultrafiltration volume; WBC, white blood cell.

${ }^{a}$ Censored patients are who subjects do not get event prior to the end of study.
Table 2. Assessment of Quality of Fitted Various Multiple Parametric AFTMSP Models Using Akaike's Information Criterion

\begin{tabular}{lcc}
\hline AFT Parametric Model & Log-likelihood & AIC Criterion* \\
\hline Exponential & -485.376 & 996.753 \\
\hline Rayleigh & -478.714 & 983.429 \\
Weibull & -468.922 & 965.844 \\
\hline Loglogistic & -464.676 & 957.353 \\
Generalized log-logistic & -462.292 & 954.583 \\
\hline Gamma & -465.685 & 959.370 \\
\hline Extended generalized gamma & -459.611 & 949.221 \\
\hline Generalized F & -461.854 & 955.707 \\
\hline
\end{tabular}

$* \mathrm{AIC}=-2 \times \log$-likelihood $+2 \mathrm{k}$ where $\mathrm{k}$ is the number of parameters in the AFT parametric model. A smaller AIC statistic suggests a better fit.

\section{Overall Kaplan-Meier survival estimates}

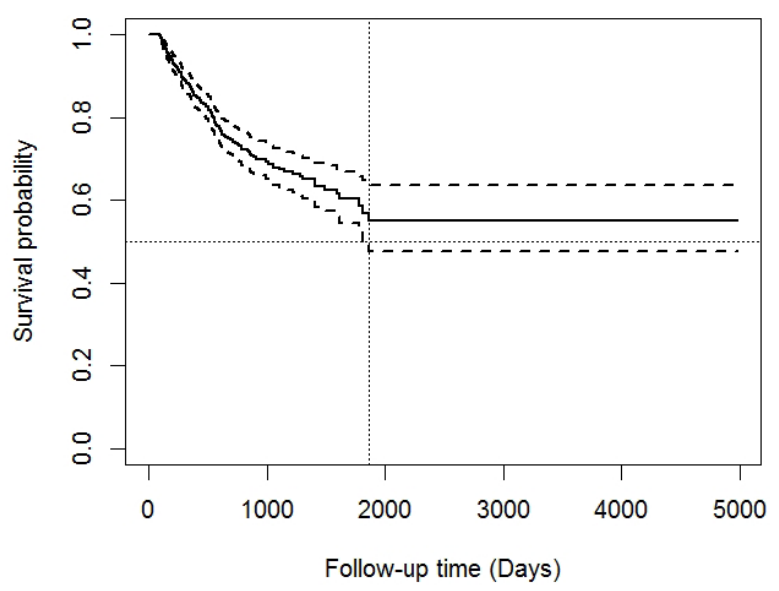

Figure 1. Overall Non-Parametric Kaplan-Meier Survival Estimates for the Study Population (Solid Line) and Its Corresponding 95\% Cl (Dashed Line) $\left[\mathrm{N}_{\text {total }}=725\right.$, Number of Death $\left.=173\right]$.

[95\% CI]: 0.90 [0.82-0.99], $P=0.023)$ were statistically significant. In addition, the adequacy of dialysis (Kt/ $\mathrm{V}_{\text {urea }}$ of $\leq 1.2$, OR [95\% CI]: 2.30 [0.93-5.56], $P=0.073$ ) and serum potassium concentration (OR $\left[\begin{array}{ll}95 \% & \mathrm{CI}\end{array}\right]$ : 0.66 [0.43-1.02], $P=0.063)$ were marginally significant predictors among patients with long-term OS (Table 3). The OR for age indicated that for every 5 -year increase in age, the likelihood of being long-term survivors decreased by almost $30 \%$. However, the OR for serum sodium and potassium concentrations suggested that each unit rise in the sodium and potassium levels was associated with an almost $10 \%$ and $34 \%$ increase in the rates of long-term OS, respectively. Patients with $\mathrm{Kt} / \mathrm{V}_{\text {urea }}$ of $>1.2$ who used AVF for HD had a higher chance of long-term survival than those with $\mathrm{Kt} / \mathrm{V}_{\text {urea }}$ of $\leq 1.2$ who used CVC for $\mathrm{HD}$.

The predicted survival probability curves for the longterm survivors are depicted in Figure 3. In the HD group with $\mathrm{Kt} / \mathrm{V}_{\text {urea }}$ of $>1.2$, the males with AVF as vascular access and high-flux HD membranes had the highest long-term OS, whereas the females with CVC as vascular access and low-flux HD membranes had the lowest long-term OS (Figure 3A). Similar results were obtained in patients with $\mathrm{Kt} / \mathrm{V}_{\text {urea }}$ of $\leq 1.2$ as well (Figure $3 \mathrm{~B}$ ). 
(A) Kaplan-Meier survival estimates by sex

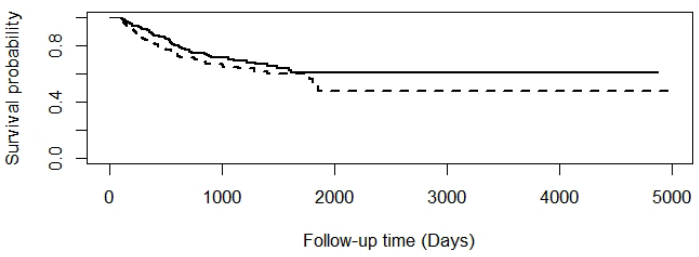

(C) Kaplan-Meier survival estimates by vascular access

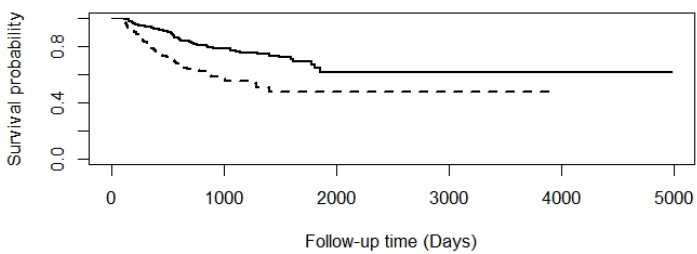

(B) Kaplan-Meier survival estimates by Kt/Vurea

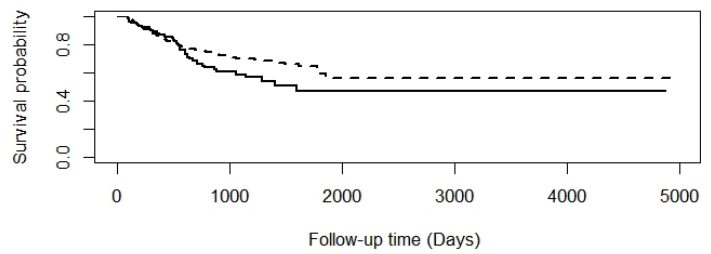

(D) Kaplan-Meier survival estimates by membrane type

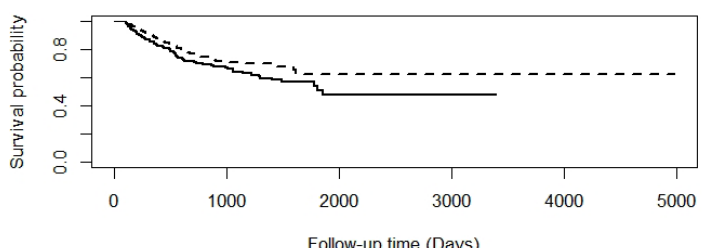

Figure 2. Overall Non-Parametric Kaplan-Meier Survival Estimates: (A) Sex: Male (Solid Line) and Female (Dashed Line) [Chi-Squared Statistics=3.95, P=0.0469]; (B) $\mathrm{Kt}_{\mathrm{V}}$ : $\leq 1.2$ (Solid Line) and $>1.2$ (Dashed Line) [Log-Rank Chi-Squared Statistics=0.0977, P=2.74]; (C) Initial Vascular Access Type: AVF (Solid Line) and CVC (Dashed Line) [Log-Rank Chi-Squared Statistics=31.58, $\mathrm{P}<0.0001]$; (D) Type of Membrane Flux: Low Flux (Solid Line) and High Flux (Dashed Line) [LogRank Chi-Squared Statistics=3.97, $\mathrm{P}=0.0462]$.

Table 3. Determinant Factors on Short- and Long-term Survival of the Study Hypertensive Patients Resulting from a Multiple Parametric AFTMSP Model When the EGG Distribution Utilized as the Best Functional Form of the Longterm OS Time

\begin{tabular}{|c|c|c|c|c|}
\hline \multicolumn{5}{|c|}{ Accelerated failure time model (Short-term Survivors) } \\
\hline Factor & & ETR & $95 \% \mathrm{Cl}$ & $P$ Value \\
\hline \multirow{2}{*}{ Sex } & Female & 1 & - & \multirow{2}{*}{$0.045^{\mathrm{a}}$} \\
\hline & Male & 1.30 & $1.006-1.639$ & \\
\hline \multirow{2}{*}{$\begin{array}{l}\text { Initial vascular } \\
\text { access type }\end{array}$} & $\mathrm{CVC}$ & 1 & - & \multirow{2}{*}{$0.005^{\mathrm{a}}$} \\
\hline & AVF & 1.50 & $1.131-1.986$ & \\
\hline \multirow{2}{*}{$\mathrm{Kt} / \mathrm{V}_{\text {urea }}$} & $>1.2$ & 1 & - & \multirow{2}{*}{0.214} \\
\hline & $\leq 1.2$ & 1.20 & $0.894-1.650$ & \\
\hline \multirow{2}{*}{$\begin{array}{l}\text { Type of membrane } \\
\text { flux }\end{array}$} & Low-Flux & 1 & - & \multirow{2}{*}{$0.064^{\mathrm{b}}$} \\
\hline & High-Flux & 1.27 & $0.986-1.647$ & \\
\hline Sodium $(\mathrm{mEq} / \mathrm{L})$ & & 0.975 & $0.944-1.008$ & 0.138 \\
\hline \multicolumn{5}{|c|}{ Logistic model (Long-term Survivors) } \\
\hline Factor & & OR & $95 \% \mathrm{Cl}$ & $P$ Value \\
\hline Age (years) & & 1.06 & $1.038-1.080$ & $<0.001^{\mathrm{a}}$ \\
\hline \multirow{2}{*}{$\begin{array}{l}\text { Initial vascular } \\
\text { access type }\end{array}$} & AVF & 1 & - & \multirow{2}{*}{$0.027^{\mathrm{a}}$} \\
\hline & CVC & 2.08 & $1.088-3.977$ & \\
\hline \multirow{2}{*}{$\mathrm{Kt} / \mathrm{V}_{\text {urea }}$} & $>1.2$ & 1 & - & \multirow{2}{*}{$0.073^{b}$} \\
\hline & $\leq 1.2$ & 2.30 & $0.927-5.565$ & \\
\hline \multicolumn{2}{|l|}{ Sodium $(\mathrm{mEq} / \mathrm{L})$} & 0.90 & $0.823-0.986$ & $0.023^{\mathrm{a}}$ \\
\hline \multicolumn{2}{|l|}{ Potassium (mEq/L) } & 0.66 & $0.426-1.023$ & $0.063^{\mathrm{b}}$ \\
\hline \multicolumn{5}{|c|}{$\begin{array}{l}\text { AFTMSP, accelerated failure time mixture split-population; } \mathrm{AVF} \text {, arteriovenous } \\
\text { fistula; } \mathrm{CVC} \text {, central venous catheter; } \mathrm{Cl} \text {, confidence interval; EGG, extendec } \\
\text { generalized gamma; ETR, event time ratio; } \mathrm{HF} \text {, high-flux; } \mathrm{Kt} / \mathrm{V}_{\text {urea' }} \text { adequacy or } \\
\text { dialysis; } \mathrm{LF} \text {, low-flux; OR, odds ratio; OS, overall survival. } \\
\text { a } P \text { value } \leq 0.05 \text { is considered significant. } \\
\text { b } P \text { value }<0.1 \text { is considered marginally significant. }\end{array}$} \\
\hline
\end{tabular}

Approximately $24 \%$ of the patients experienced death. As shown in Figure 1, the empirical value of the long-term OS proportion was $76 \%$ in about 14 years. The long-term OS rate can be easily calculated from the estimation of the parameters in the incidence (or long-term OS) part. The results demonstrated that the patients who underwent
Table 4. Estimated Long-term OS Proportions Using Extended Generalized Gamma AFTMSP Model

\begin{tabular}{lcccc}
\hline \multirow{2}{*}{ Prognostic Factor } & & \multicolumn{2}{c}{ Kt// } & \multicolumn{2}{c}{$\begin{array}{c}\text { Relative } \\
\text { Percentage }^{\mathbf{a}}\end{array}$} \\
\cline { 2 - 4 } $\begin{array}{l}\text { Initial vascular } \\
\text { access type }\end{array}$ & CVC & 29.1 & 48.3 & $+66.0 \%$ \\
\cline { 2 - 4 } & AVF & 46.1 & 66.0 & $+43.2 \%$ \\
\hline Relative percentage $^{\mathrm{a}}$ & & $+58.4 \%$ & $+36.6 \%$ & -
\end{tabular}

$\overline{\text { AFTMSP, accelerated failure time mixture split-population; AVF, arteriovenous }}$ fistula; $\mathrm{CVC}$, central venous catheter; $\mathrm{Kt} / \mathrm{V}$, adequacy of dialysis.

${ }^{+}$Positive (+) sign indicates an increase in relative percentage of the long-term OS rate.

dialysis with AVF vascular access and an acceptable level of dialysis adequacy $\left(\mathrm{Kt} / \mathrm{V}_{\text {urea }}\right.$ of $\left.>1.2\right)$ had the highest longterm OS rates $(66 \%)$. In addition, receiving inadequate dialysis $\left(\mathrm{Kt} / \mathrm{V}_{\text {urea }}\right.$ of $\left.\leq 1.2\right)$ with CVC vascular access for $\mathrm{HD}$ led to the lowest long-term OS rate (Table 4).

\section{Discussion}

The management of hypertension among HD populations has often been neglected and the high cardiovascular mortality in these patients is often attributed to elevated blood pressure. ${ }^{36}$ To the best of our knowledge, this is the first study which used the parametric AFTMSP model for a large number of HTN-HD patients. It mainly highlighted the prognostic factors with a great impact on short- and long-term OS. Furthermore, the pivotal covariates that could change the risk of death were specified.

Recently, many studies have reported the effects of different prognostic determinants on the short-term OS of patients in the general HD population. These studies utilized the Log-rank test, the standard Cox $\mathrm{PH}$ regression, or parametric models which are suitable techniques for analyzing short-term OS. ${ }^{2,5,11,12,16,18,37}$ Moreover, among the various parametric models, the log-normal and Weibull distributions had better performance than Cox regression. ${ }^{11,12}$

MSP models are more appropriate than Cox regression 
(A) $\mathrm{Kt} / \mathrm{V}$ greater than 1.2

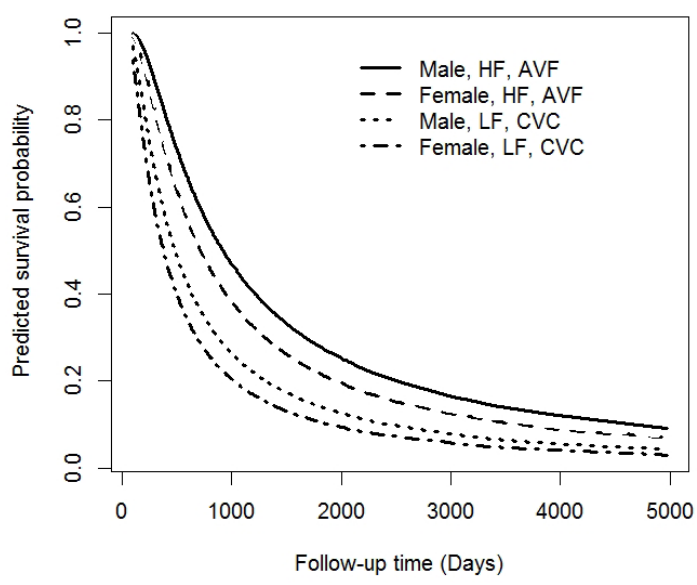

(B) $\mathrm{Kt} / \mathrm{V}$ less than or equal 1.2

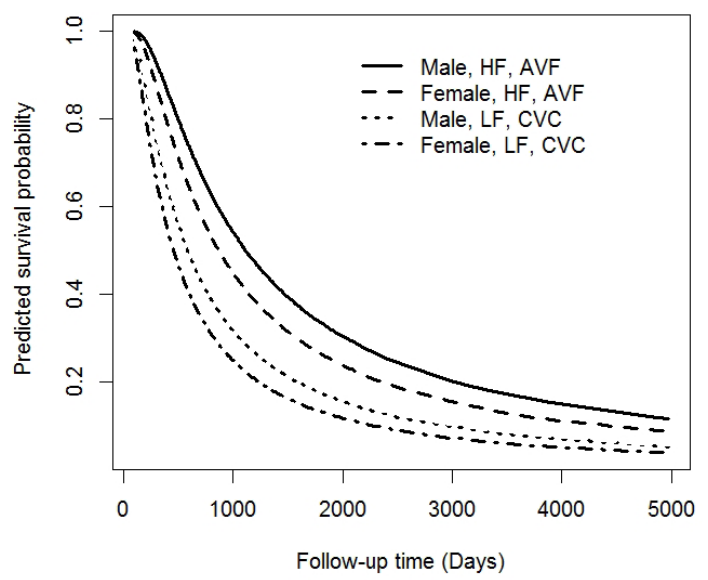

Figure 3. Predicted Survival Probabilities for Long-Term Survivors Based on the Extended Generalized Gamma AFTMSP Model [(A): Kt/V $>1.2$ and (B): Kt/ $\left.\mathrm{V}_{\text {urea }} \leq 1.2\right]$.

in cases with long follow-up and a high censoring rate..$^{29,34}$ In our dataset, the estimated NPKM plot leveled off around 0.55 and a long plateau (almost 8.5 years) was observed over time. Thus, the AFTMSP analysis was applied to eight different parametric distributions. The results showed that the EGG model was superior to the others based on the AIC criterion and was chosen as the best functional form of the OS time.

The results of the optimal AFTMSP regression indicated that sex, initial vascular access type, and membrane flux type had significant effects on the short-term OS, while age, initial vascular access type, adequacy of dialysis (measured by single-pool Kt/V), and serum concentrations of sodium and potassium affected the long-term OS of the HTN-HD patients.

This study showed a higher short-term OS time in men and also a reduction in the odds of long-term OS with increase in age. Age and sex have also been important determinants for the survival of HD patients in most previous studies which is in line with the results of the present research. ${ }^{12,38,39}$ In the general population, women have a survival advantage over men which is in contrast with the findings in HD populations. ${ }^{39}$ Some researchers demonstrated that sex played a significant role in determining OS in HD patients and that the mortality rate was lower in females than males. These are inconsistent with the current study. ${ }^{40,41}$ This disparity is possibly due to the different HD populations studied. In addition, the present study was specifically conducted on the HTN-HD population. Another study on HD patients showed no significant differences in the mortality rate based on sex and age group. ${ }^{2}$

In the present study, $45 \%$ of the patients had CVC as initial vascular access and the empirical death rate in this group was about $31 \%$ which was much higher than that of the AVF group (18\%). The OS at 1, 3, and 5 years was respectively $78.4 \%, 55.6 \%$, and $49.0 \%$ in the CVC group and $93.0 \%, 76.8 \%$, and $65.1 \%$ in the AVF group. These OS proportions were higher than those calculated by Shibiru et al. ${ }^{2}$ This difference can be partly explained by the long interval between the two studies (8 years), different sample sizes and study designs, the patients' comorbid illness, and the great improvement in health services during this period. According to the results of the MSP regression, using AVF as the initial access for HD therapy was beneficial for both the short- and longterm survivor groups. A study conducted on the HD population of Ethiopia demonstrated that there was a significant relationship between the use of CVC and the reduction in short- and long-term OS rates. ${ }^{2}$ However, several studies have reported a considerable variation in the mortality rate based on the type of vascular access (AVF or CVC). The highest mortality rate was observed for the CVC type. . $^{1,42,43}$

About $65 \%$ of the patients were treated with a highflux dialyzer. The empirical death rates in the high- and low-flux groups were $20.3 \%$ and $30.4 \%$, respectively, indicating a $50 \%$ relative increase in the hazard of death. Similarly, according to other studies, a reduction in death rate $(24 \%-38 \%)$ was observed in HD patients with a high-flux membrane compared to those with a low-flux membrane. ${ }^{44,45}$ The AFTMSP analysis showed that patients with a high-flux HD had a longer shortterm OS time than those with a low-flux HD. There is some explanation for the shorter OS time of patients with a low-flux dialyzer membrane compared to those with a high-flux one. Patients on maintenance HD start to develop complications from the accumulation of $\beta_{2}$ microglobulin after several years of dialysis treatment. ${ }^{46}$ HD using high-flux membranes can more effectively clear $\beta_{2}$-microglobulin than regular dialysis using lowflux membranes. ${ }^{47,48}$ In a meta-analysis by Zhao et al, the superior effectiveness of the high-flux HD on OS has also been confirmed. ${ }^{49}$ Furthermore, in 2014, the results of a systematic review showed that dialysis using a highflux membrane did not reduce all-cause mortality rate. However, it diminished cardiovascular mortality rate compared to dialysis using a low-flux membrane..$^{50}$ 
The mixture analysis demonstrated that the patients who received a higher dose of dialysis had a long-term OS advantage over those who received a lower dose of dialysis. In addition, $\mathrm{Kt} / \mathrm{V}_{\text {urea }}$ of $>1.2$ increased the long-term OS rate $60.0 \%$ and $43.2 \%$ in the CVC and AVF groups, respectively, compared to $\mathrm{Kt} / \mathrm{V}_{\text {urea }}$ of $\leq 1.2$. Previous papers have indirectly confirmed the positive effect of a highquality dialysis on the OS and long-term survival rate of patients undergoing maintenance HD. ${ }^{20,39,41}$ The subgroup analysis based on the adequacy of dialysis (Figure 3) showed that the initial vascular access type and membrane flux were the most important prognostic determinants of long-term OS. Regardless of the patients' sex and dialysis adequacy groups, the results of the current study suggested that hypertensive patients with AVF and a high-flux membrane had the highest long-term OS rate compared to those who underwent dialysis with CVC and a low-flux membrane. Furthermore, the patients with inadequate dialysis $\left(\mathrm{Kt} / \mathrm{V}_{\text {urea }}\right.$ of $\left.\leq 1.2\right)$ who had used AVF as the initial vascular access had a $58.4 \%$ higher long-term OS rate than those who had used CVC.

Serum potassium concentration was able to prolong the long-term OS rate since it decreased death hazard by $34 \%$ with every one-unit increase in its level up to $5.5 \mathrm{mEq} / \mathrm{L}$ (the threshold of hyperkalemia). Previous publications showed that the serum potassium level of 4.6-5.3 $\mathrm{mEq} / \mathrm{L}$ was associated with the highest OS rate, whereas the serum potassium level of $<4.0$ or $>5.7 \mathrm{mEq} / \mathrm{L}$ increased the mortality rate. ${ }^{21,51} \mathrm{~A}$ review of the literature demonstrated that the longer the interdialytic interval, the greater the odds of hyperkalemia. This shows that hyperkalemia due to a long interdialytic interval ( $>48$ hours) is associated with the death of HTN-HD patients. ${ }^{21,52}$

Besides, serum sodium concentration plays an essential role in long-term OS. Each 1-mEq/L increment in serum sodium (considered as a continuous covariate) can decrease the death rate by $10 \%$. Previous investigations confirmed the hypothesis that hyponatremia (serum sodium concentration less than $135 \mathrm{mEq} / \mathrm{L}$ ) may be itself a causal determinant of HD-related death. ${ }^{12,37,53,54}$ The empirical mortality rate of the patients in the hyponatremia group was $30 \%$ which was much higher than that of the non-hyponatremia group (23\%). The reason why a low serum sodium level may affect long-term OS is not exactly clear. Moreover, the importance of hyponatremia as an independent risk factor for HD-related death can be explained from different perspectives. Shorter dialysis sessions enhance the risk of failure to obtain enough sodium concentration and may have a negative effect on the outcome..$^{53,54}$

The duration of follow-up was more than 13 years (4883 days) which was the strength of the split-population analysis in the current study. The other strong points of the present study were the considerable number of individuals who enrolled in this research and using demographic and laboratory features as well as HD session-related indices. A major weakness of this study was that the cause of death was not specified in the database. Besides, it should be noted that since hypertensive patients undergoing $\mathrm{HD}$ receive appropriate medical care, the results may be confounded. Due to the large number of features, it was not possible to fit the AFTMSP model with all of them. Therefore, variable selection methods such as LASSO and elastic-net should be utilized to select the best subset of prognostic factors.

In conclusion, the split-population analysis is a powerful statistical technique for assessing the determinants of OS in both short- and long-term survivors. The findings of the current study demonstrated that the female sex, aging, and dialysis with a low-flux HD membrane and CVC as vascular access were associated with a poorer prognosis in HTN-HD patients. Furthermore, high levels of sodium and potassium concentrations, $\mathrm{Kt} / \mathrm{V}_{\text {urea }}$ of $>1.2$, and $\mathrm{AVF}$ vascular access increased the probability of long-term OS. These findings can be considered by health policy decision-makers in creating a new guideline to improve the long-term OS of HTN-HD patients. Nevertheless, further investigations are required to extend the existing knowledge beyond the survivors of HD and to develop MSP models more comprehensively so that they can illustrate how the determinants of survival may be different for short- and long-term survivors.

\section{Authors' Contribution}

VE: get the idea, designed, data acquisition, data analysis, and supervised the study. VE and SS: wrote the original manuscript version. VE, MS, MHK, PJ, SEJ and SS had contributions in the interpretation of data and manuscript editing. All authors have read and confirmed the final draft.

\section{Conflict of Interest Disclosures}

The authors declare no conflicts of interest.

\section{Ethical Statement}

This work was supported by the Research Council of Shiraz University of Medical Sciences (SUMS), Shiraz, Iran (grant No. 1396-01-08-15364) and was approved by the Vice-Chancellor of Research and Technology as well as the Ethics Committee of SUMS (IR.SUMS.REC.1396.S828).

\section{Acknowledgements}

We would like to thank the members of the SUMS special diseases department staff for their support and cooperation in data collection.

\section{Supplementary Materials}

Supplementary file 1. Mixture Split-Population Models.

\section{References}

1. do Sameiro-Faria M, Ribeiro S, Costa E, Mendonça D, Teixeira L, Rocha-Pereira P, et al. Risk factors for mortality in hemodialysis patients: two-year follow-up study. Dis Markers. 2013;35(6):791-8. doi: 10.1155/2013/518945.

2. Shibiru T, Gudina EK, Habte B, Deribew A, Agonafer T. Survival patterns of patients on maintenance hemodialysis for end stage renal disease in Ethiopia: summary of 91 cases. BMC Nephrol. 2013;14(1):127. doi: 10.1186/1471-2369-14-127.

3. Taherpour S, Javanmard D, Ziaee M. Occult hepatitis C virus infection among hemodialysis patients: an Iranian experience. Arch Iran Med. 2020;23(9):586-92. doi: 10.34172/ 
aim.2020.68.

4. Jeon HJ, Bae HJ, Ham YR, Choi DE, Na KR, Ahn MS, et al. Outcomes of end-stage renal disease patients on the waiting list for deceased donor kidney transplantation: a singlecenter study. Kidney Res Clin Pract. 2019;38(1):116-23. doi: 10.23876/j.krcp.18.0068.

5. Khazaei S, Yaseri M, Nematollahi S, Zobdeh Z, Sheikh V, Mansournia MA. Survival rate and predictors of mortality among hemodialysis patients in West of Iran, 1996-2015. Int J Prev Med. 2018;9:113. doi: 10.4103/ijpvm.IJPVM_399_16.

6. Ezzatzadegan Jahromi S, Haghighi G, Roozbeh J, Ebrahimi V. Comparisons between different blood pressure measurement techniques in patients with chronic kidney disease. Kidney Res Clin Pract. 2019;38(2):212-9. doi: 10.23876/j.krcp.18.0109.

7. Amraoui F, Bos S, Vogt L, van den Born BJ. Long-term renal outcome in patients with malignant hypertension: a retrospective cohort study. BMC Nephrol. 2012;13:71. doi: 10.1186/1471-2369-13-71.

8. Bikos A, Angeloudi E, Memmos E, Loutradis C, Karpetas A, Ginikopoulou E, et al. A comparative study of short-term blood pressure variability in hemodialysis patients with and without intradialytic hypertension. Am J Nephrol. 2018;48(4):295305. doi: 10.1159/000493989.

9. Kramer A, Pippias M, Noordzij M, Stel VS, Afentakis N, Ambühl PM, et al. The European Renal Association - European Dialysis and Transplant Association (ERA-EDTA) registry annual report 2015: a summary. Clin Kidney J. 2018;11(1):108-22. doi: 10.1093/ckj/sfx149.

10. Saran R, Robinson B, Abbott KC, Agodoa LY, Albertus P, Ayanian J, et al. US renal data system 2016 annual data report: epidemiology of kidney disease in the United States. Am J Kidney Dis. 2017;69(3 Suppl 1):A7-A8. doi: 10.1053/j. ajkd.2016.12.004.

11. Montaseri M, Yazdani Charati J, Espahbodi F. Application of parametric models to a survival analysis of hemodialysis patients. Nephrourol Mon. 2016;8(6):e28738. doi: 10.5812/ numonthly.28738.

12. Ebrahimi V, Khademian MH, Masoumi SJ, Morvaridi MR, Ezzatzadegan Jahromi S. Factors influencing survival time of hemodialysis patients; time to event analysis using parametric models: a cohort study. BMC Nephrol. 2019;20(1):215. doi: 10.1186/s12882-019-1382-2.

13. Assimon MM, Wenger JB, Wang L, Flythe JE. Ultrafiltration rate and mortality in maintenance hemodialysis patients. Am J Kidney Dis. 2016;68(6):911-22. doi: 10.1053/j. ajkd.2016.06.020.

14. Beberashvili I, Sinuani I, Azar A, Kadoshi H, Shapiro G, Feldman $\mathrm{L}$, et al. Low serum concentration of obestatin as a predictor of mortality in maintenance hemodialysis patients. Biomed Res Int. 2013;2013:796586. doi: 10.1155/2013/796586.

15. Inaguma D, Koide S, Takahashi K, Hayashi H, Hasegawa M, Yuzawa $Y$, et al. Relationship between serum calcium level at dialysis initiation and subsequent prognosis. Ren Replace Ther. 2017;3(1):2. doi: 10.1186/s41100-016-0087-2.

16. Kim CS, Jin DC, Yun YC, Bae EH, Ma SK, Kim SW. Relationship between serum uric acid and mortality among hemodialysis patients: retrospective analysis of Korean end-stage renal disease registry data. Kidney Res Clin Pract. 2017;36(4):36876. doi: 10.23876/j.krcp.2017.36.4.368.

17. Moradi H, Streja E, Kashyap ML, Vaziri ND, Fonarow GC, Kalantar-Zadeh K. Elevated high-density lipoprotein cholesterol and cardiovascular mortality in maintenance hemodialysis patients. Nephrol Dial Transplant. 2014;29(8):1554-62. doi: 10.1093/ndt/gfu022.

18. Park JM, Lee JH, Jang HM, Park Y, Kim YS, Kang SW, et al. Survival in patients on hemodialysis: effect of gender according to body mass index and creatinine. PLoS One. 2018;13(5):e0196550. doi: 10.1371/journal.pone.0196550.
19. Roozbeh J, Serati AR, Malekhoseini SA. Arteriovenous fistula thrombosis in patients on regular hemodialysis: a report of 171 patients. Arch Iran Med. 2006;9(1):26-32.

20. Song KK, Zhao DL, Wang YD, Wang Y, Sun XF, Miao LN, et al. Analysis of factors associated with death in maintenance hemodialysis patients: a multicenter study in China. Chin Med J (Engl). 2017;130(8):885-91. doi: 10.4103/03666999.204103.

21. Yusuf AA, Hu Y, Singh B, Menoyo JA, Wetmore JB. Serum potassium levels and mortality in hemodialysis patients: a retrospective cohort study. Am J Nephrol. 2016;44(3):179-86. doi: 10.1159/000448341.

22. Therneau T, Grambsch P. Modeling Survival Data: Extending the Cox Model. New York, NY: Springer Science \& Business Media; 2013.

23. Christensen E. Multivariate survival analysis using Cox's regression model. Hepatology. 1987;7(6):1346-58. doi: 10.1002/hep.1840070628.

24. Kleinbaum DG, Klein M. Survival Analysis: A Self-Learning Text. New York: Springer-Verlag; 2016.

25. Efron B. The efficiency of Cox's likelihood function for censored data. J Am Stat Assoc. 1977;72(359):557-65. doi: 10.1080/01621459.1977.10480613.

26. Altman DG, De Stavola BL, Love SB, Stepniewska KA. Review of survival analyses published in cancer journals. Br J Cancer. 1995;72(2):511-8. doi: 10.1038/bjc.1995.364.

27. Nardi A, Schemper M. Comparing Cox and parametric models in clinical studies. Stat Med. 2003;22(23):3597-610. doi: 10.1002/sim.1592.

28. Maller RA, Zhou X. Survival Analysis with Long-Term Survivors. New York: John Wiley \& Sons; 1996.

29. Othus M, Barlogie B, Leblanc ML, Crowley JJ. Cure models as a useful statistical tool for analyzing survival. Clin Cancer Res. 2012;18(14):3731-6. doi: 10.1158/1078-0432.ccr-11-2859.

30. Cai C, Zou Y, Peng Y, Zhang J. smcure: an R-package for estimating semiparametric mixture cure models. Comput Methods Programs Biomed. 2012;108(3):1255-60. doi: 10.1016/j.cmpb.2012.08.013.

31. Momeni A, Rouhi H, Kiani G, Amiri M. Effects of high-flux versus low-flux membranes on pulmonary function tests in hemodialysis patients. Tanaffos. 2013;12(1):31-5.

32. Daugirdas JT. Second generation logarithmic estimates of single-pool variable volume $\mathrm{Kt} / \mathrm{V}$ : an analysis of error. J Am Soc Nephrol. 1993;4(5):1205-13. doi: 10.1681/asn.v451205.

33. Golper T, Burkart J, Blake P, Chattoh D, Churchill D, Firanek C, et al. NKF-K/DOQI clinical practice guidelines for peritoneal dialysis adequacy: update 2000. Am J Kidney Dis. 2001;37(1 Suppl 1):S65-S136. doi: 10.1016/s0272-6386(01)70006-6.

34. Lam KF, Fong DY, Tang OY. Estimating the proportion of cured patients in a censored sample. Stat Med. 2005;24(12):186579. doi: 10.1002/sim.2137.

35. Peng $Y$, Dear KB, Denham JW. A generalized $F$ mixture model for cure rate estimation. Stat Med. 1998;17(8):81330. doi: 10.1002/(sici)1097-0258(19980430)17:8<813::aid$\operatorname{sim} 775>3.0 . \mathrm{co} ; 2-\#$

36. Tozawa M, Iseki K, Iseki C, Takishita S. Pulse pressure and risk of total mortality and cardiovascular events in patients on chronic hemodialysis. Kidney Int. 2002;61(2):717-26. doi: 10.1046/j.1523-1755.2002.00173.x.

37. Nagai K, Matsuura M, Tsuchida K, Kanayama HO, Doi T, Minakuchi J. Prognostic factors for mortality in middle-aged and older hemodialysis patients: a 5-year observational study. J Artif Organs. 2018;21(1):94-101. doi: 10.1007/s10047-0170993-2.

38. Ríos Á, Herrera P, Morales Á, Reynolds E, Fernández MB González F. [Survival of older patients starting hemodialysis in Chile]. Rev Med Chil. 2016;144(6):697-703. doi: 10.4067/ s0034-98872016000600002. [Spanish]. 
39. Vongsanim S, Davenport A. The effect of gender on survival for hemodialysis patients: why don't women live longer than men? Semin Dial. 2019;32(5):438-43. doi: 10.1111/sdi.12817.

40. Depner T, Daugirdas J, Greene T, Allon M, Beck G, Chumlea $C$, et al. Dialysis dose and the effect of gender and body size on outcome in the HEMO Study. Kidney Int. 2004;65(4):138694. doi: 10.1111/j.1523-1755.2004.00519.x.

41. Charra B, Calemard E, Ruffet M, Chazot C, Terrat JC, Vanel T, et al. Survival as an index of adequacy of dialysis. Kidney Int. 1992;41(5):1286-91. doi: 10.1038/ki.1992.191.

42. de Sousa-Martins P, Moura A, Madureira J, Alija P, Oliveira JG, Lopez M, et al. Risk factors for mortality in end-stage kidney disease patients under online-hemodiafiltration: threeyear follow-up study. Biomarkers. 2016;21(6):544-50. doi: 10.3109/1354750x.2016.1160428.

43. Port FK, Pisoni RL, Bommer J, Locatelli F, Jadoul M, Eknoyan $\mathrm{G}$, et al. Improving outcomes for dialysis patients in the international Dialysis Outcomes and Practice Patterns Study. Clin J Am Soc Nephrol. 2006;1(2):246-55. doi: 10.2215/ cjn.01050905.

44. Port FK, Wolfe RA, Hulbert-Shearon TE, Daugirdas JT, Agodoa $\mathrm{LY}$, Jones $\mathrm{C}$, et al. Mortality risk by hemodialyzer reuse practice and dialyzer membrane characteristics: results from the USRDS dialysis morbidity and mortality study. Am J Kidney Dis. 2001;37(2):276-86. doi: 10.1053/ajkd.2001.21290.

45. Chauveau P, Nguyen H, Combe C, Chêne G, Azar R, Cano $\mathrm{N}$, et al. Dialyzer membrane permeability and survival in hemodialysis patients. Am J Kidney Dis. 2005;45(3):565-71. doi: 10.1053/j.ajkd.2004.11.014.

46. Bouré $T$, Vanholder R. Biochemical and clinical evidence for uremic toxicity. Artif Organs. 2004;28(3):248-53. doi: 10.1111/j.1525-1594.2004.47315.x.

47. Bloembergen WE, Hakim RM, Stannard DC, Held PJ, Wolfe RA, Agodoa LY, et al. Relationship of dialysis membrane and cause-specific mortality. Am J Kidney Dis. 1999;33(1):1-10. doi: 10.1016/s0272-6386(99)70251-9.

48. Eknoyan G, Beck GJ, Cheung AK, Daugirdas JT, Greene T, Kusek JW, et al. Effect of dialysis dose and membrane flux in maintenance hemodialysis. N Engl J Med. 2002;347(25):20109. doi: 10.1056/NEJMoa021583.

49. Zhao F, Wang Z, Liu L, Wang S. The influence of mortality rate from membrane flux for end-stage renal disease: a metaanalysis. Nephrol Ther. 2017;13(1):9-13. doi: 10.1016/j. nephro.2016.07.445.

50. Slinin Y, Greer N, Ishani A, MacDonald R, Olson C, Rutks $\mathrm{I}$, et al. Timing of dialysis initiation, duration and frequency of hemodialysis sessions, and membrane flux: a systematic review for a KDOQI clinical practice guideline. Am J Kidney Dis. 2015;66(5):823-36. doi: 10.1053/j.ajkd.2014.11.031.

51. Kovesdy CP, Regidor DL, Mehrotra R, Jing J, McAllister C), Greenland S, et al. Serum and dialysate potassium concentrations and survival in hemodialysis patients. Clin J Am Soc Nephrol. 2007;2(5):999-1007. doi: 10.2215/ cjn.04451206.

52. Foley RN, Gilbertson DT, Murray T, Collins AJ. Long interdialytic interval and mortality among patients receiving hemodialysis. N Engl J Med. 2011;365(12):1099-107. doi: 10.1056/NEJMoa1103313.

53. Waikar SS, Curhan GC, Brunelli SM. Mortality associated with low serum sodium concentration in maintenance hemodialysis. Am J Med. 2011;124(1):77-84. doi: 10.1016/j. amjmed.2010.07.029.

54. Hecking M, Karaboyas A, Saran R, Sen A, Hörl WH, Pisoni RL, et al. Predialysis serum sodium level, dialysate sodium, and mortality in maintenance hemodialysis patients: the Dialysis Outcomes and Practice Patterns Study (DOPPS). Am J Kidney Dis. 2012;59(2):238-48. doi: 10.1053/j.ajkd.2011.07.013. 